\title{
The novel carboxamide analog ITR-284 induces caspase-dependent apoptotic cell death in human hepatocellular and colorectal cancer cells
}

\author{
YU-REN LIAO ${ }^{1}$, CHI-CHENG LU ${ }^{2}$, KUANG-CHI LAI ${ }^{3,4}$, JAI-SING YANG ${ }^{5}$, SHENG-CHU KUO ${ }^{6}$, \\ YEN-FANG WEN $^{7}$, SHINJI FUSHIYA ${ }^{8}$ and TIAN-SHUNG WU ${ }^{1}$
}

\author{
${ }^{1}$ Department of Chemistry, National Cheng Kung University, Tainan $701 ;{ }^{2}$ Department of Life Sciences, \\ National Chung Hsing University, Taichung 402; ${ }^{3}$ School of Medicine, China Medical University, Taichung 404; \\ ${ }^{4}$ Department of Surgery, China Medical University Beigang Hospital, Yunlin 651; ${ }^{5}$ Department of Pharmacology; \\ ${ }^{6}$ Graduate Institute of Pharmaceutical Chemistry, China Medical University, Taichung 404; ${ }^{7}$ Medicinal Chemistry Laboratory, \\ Biomedical Engineering Research Laboratories, Industrial Technology Research Institute, Hsinchu 300, Taiwan, R.O.C.; \\ ${ }^{8}$ Department of Kampo Pharmaceutical Sciences, Nihon Pharmaceutical University, Saitama 362-0806, Japan
}

Received July 27, 2012; Accepted November 21, 2012

DOI: $10.3892 / \mathrm{mmr} .2013 .1359$

\begin{abstract}
We have previously reported that ITR-284, a potent carboxamide-derived anticancer agent, induced apoptosis in leukemia cells. However, there are no reports showing that ITR-284 inhibits human hepatocellular and colorectal cancer cells. In this study, we investigated the antiproliferative effects and apoptotic induction of ITR-284 on various types of human hepatocellular and colorectal cancer cells in vitro. The growth inhibition effect of ITR-284 on cancer cells was evaluated by thiazolyl blue tetrazolium bromide (MTT) assay. Cell morphology was examined under a phase-contrast microscope. The activities of caspase- $3,-8$ and -9 were determined by caspase colorimetric assay. ITR-284 reduced the cell viability in human hepatocellular cancer cells (Hep G2, Hep 3B, SK-HEP-1 and J5) and colorectal cancer cells (HT 29, COLO 205, HCT 116 and SW 620). ITR-284 had highly selective effects on Hep 3B and COLO 205 cells. ITR-284 stimulated morphological changes of Hep 3B and COLO 205 cells. The activation of caspase- $3,-8$ and -9 contributed to ITR-284-induced apoptosis. ITR-284-triggered growth inhibition was significantly attenuated by the inhibitors of caspase-3, -8 and -9 in Hep 3B and COLO 205 cells. ITR-284 induced apoptosis in Hep 3B and COLO 205 cells through the caspase cascade-dependent signaling pathway.
\end{abstract}

Correspondence to: Dr Tian-Shung Wu, Department of Chemistry, National Cheng Kung University, No. 1 Ta-Hsueh Road, Tainan 701, Taiwan, R.O.C

E-mail: tswu@mail.ncku.edu.tw

Key words: ITR-284, apoptosis, caspase, Hep 3B cells, COLO 205 cells

\section{Introduction}

Cancer is a major cause of mortality worldwide and in Taiwan (1). Liver cancer is the second most frequent cause of cancer death, and colorectal cancer is the third most frequent cause of cancer death in Taiwan $(2,3)$. Approximately 26.0 per 100,000 individuals succumb to liver cancer and 25.3 per 100,000 individuals succumb to colorectal cancer each year, according to the Department of Health, Executive Yuan, Taiwan in 2010 (www.doh.gov.tw/CHT2006/DM/DM2_2. aspx?now_fod_list_no $=12336 \&$ class_no $\left.=440 \& l e v e l \_n o=4\right)$. Chemotherapy is one of the treatment options in liver and colorectal cancer, but the anticancer effects of chemotherapeutic agents are not fully satisfactory. Thus, the discovery of new antiliver and anticolorectal cancer chemotherapeutic agents is urgently required. The induction of cancer cell apoptosis has been shown to be the major anticancer mechanism for chemotherapeutic agents $(4,5)$. Apoptosis has stimulated interest in caspases as potential therapeutic targets of chemotherapeutic agents $(6,7)$.

Previously, we designed and synthesized a series of carboxamide derivatives as novel anticancer agents (8). We found that many of these compounds exhibited potent cytotoxicities against various human cancer cell lines $(8,9)$. ITR-284 [N-(2-Dimethylaminoethyl)-4,8-dihydrobenzo (1,2-b;4,5-b') dithio-phene-2- carboxamide phosphoric acid salt] (Fig. 1A) is one of the most potent agents. The previous studies suggested that ITR-284 significantly inhibited the proliferation of HL60 and WEHI-3 leukemia cells, with low toxicity to normal cells $(8,9)$. In the current study, we investigated the antiproliferative effects and apoptotic induction of ITR-284 on human hepatocellular cancer cell lines (Hep G2, Hep 3B, SK-HEP-1 and J5) and colorectal cancer cell lines (HT 29, COLO 205, HCT 116 and SW 620). We demonstrated that ITR-284 has a greater growth inhibition effect than that of other compounds in various cancer cells, with a half maximal effective concen- 
tration $\left(\mathrm{EC}_{50}\right)$ of 50 to $75 \mathrm{nM}$. We explored the mechanism of apoptotic induction by ITR-284 in Hep 3B and COLO 205 cells. Our results suggest that ITR-284 induced apoptosis in Hep 3B and COLO 205 cells through caspase cascade-mediated pathways. ITR-284 may be selected as the lead compound of an antihepatocellular and colorectal cancer agent to trigger cell apoptosis in the future.

\section{Materials and methods}

Chemicals and reagents. MTT [3-(4,5-dimethylthiazol2-yl)-2,5-diphenyltetrazolium bromide] was purchased from Sigma-Aldrich Corp. (St. Louis, MO, USA). Fetal bovine serum (FBS), L-glutamine, penicillin-streptomycin, cell culture medium DMEM and trypsin-EDTA were obtained from Gibco/Life Technologies (Carlsbad, CA, USA). Caspase-3 (Z-DEVE-FMK), -8 (Z-IETD-FMK) and -9 (Z-LEHD-FMK) inhibitors were dissolved in DMSO and diluted in cell culture medium prior to use (R\&D Systems, Minneapolis, MN, USA).

Cell culture. The human hepatocellular cancer cell lines (Hep G2, Hep 3B, SK-HEP-1 and J5) and human colorectal cancer cell lines (HT 29, COLO 205, HCT 116 and SW 620) were purchased from the Food Industry Research and Development Institute (Hsinchu, Taiwan). All cells were cultured with DMEM and plated into a 75-T flask with $2 \mathrm{mM}$ L-glutamine and were adjusted to contain 10\% FBS and 1\% penicillin-streptomycin $(100 \mathrm{U} / \mathrm{ml}$ penicillin and $100 \mu \mathrm{g} / \mathrm{ml}$ streptomycin). All cells were grown at $37^{\circ} \mathrm{C}$ in a humidified atmosphere comprised of $95 \%$ air and $5 \% \mathrm{CO}_{2}$.

Cell viability assay. Cell viability was assessed using the MTT assay as described previously $(10,11)$. Approximately $2 \times 10^{4}$ cells/well were plated onto 96-well plates and then were exposed to ITR-284 (0, 20, 40, 60, 80 and $100 \mathrm{nM})$. DMSO $(0.1 \%)$ in media served as a vehicle control. Cell viability was also used to examine Hep 3B and COLO 205 cells following pretreatment with or without $10 \mu \mathrm{M}$ of caspase-3, -8 and -9 inhibitors for $1 \mathrm{~h}$, followed by treatment with $50 \mathrm{nM}$ ITR-284 and $0.1 \%$ DMSO as a control. After a 48-h incubation, $100 \mu \mathrm{l}$ of MTT solution $(0.5 \mathrm{mg} / \mathrm{ml})$ was added to each well, and the plate was incubated at $37^{\circ} \mathrm{C}$. Approximately $100 \mu \mathrm{l}$ of $0.04 \mathrm{M}$ $\mathrm{HCl} /$ isopropanol was added and the absorbance at $570 \mathrm{~nm}$ was measured for each well. The cell survival ratio was expressed as a percentage of the control. All results were formed of three independent experiments.

Cell morphological examination. A total of $2 \times 10^{5}$ cells/well of Hep 3B and COLO 205 cells in 24-well plates were exposed to $50 \mathrm{nM}$ ITR-284 for $48 \mathrm{~h}$. The cell morphology was directly examined and images were captured under a contrast-phase microscope (12).

Assays for caspase-3, - 8 and -9 activities. The activities of caspase- $3,-8$ and -9 were determined according to the manufacturer's instructions (Caspase colorimetric kits, R\&D Systems). Hep 3B and COLO 205 cells were inoculated into a 75-T flask at a density of $1 \times 10^{7}$. After being treated with ITR-284 $(50 \mathrm{nM})$ for $48 \mathrm{~h}$, cells were harvested and lysed

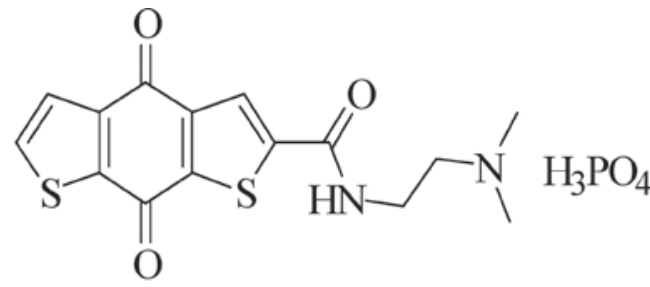

\section{ITR-284}

(N-(2-Dimethylaminoethyl)-4,8-dihydrobenzo [1,2-b;4,5-b'] dithio-phene-2-carboxamide phosphoric acid salt)

Figure 1. Chemical structure of ITR-284.

in lysis buffer $(50 \mu \mathrm{l})$ for $10 \mathrm{~min}$. After centrifugation, the supernatants containing $100 \mu \mathrm{g}$ protein were incubated with caspase-3, -8 and -9 substrate (Z-DEVE-pNA, Z-IETD-pNA and Z-LEHD-pNA for caspase-3, -8 and -9 , respectively) in reaction buffer. Samples were incubated in a 96-well flat-bottomed microplate at $37^{\circ} \mathrm{C}$ for $1 \mathrm{~h}$. The levels of released pNA were measured with an ELISA reader (Anthos Labtec Instruments $\mathrm{GmbH}$, Salzburg, Austria) at a wavelength of $405 \mathrm{~nm}(13,14)$.

Statistical analysis. The statistical results were expressed as the means \pm SEM of triplicate samples, and the difference between groups was analyzed using a two-tailed Student's t-test. $P<0.001$ was considered to indicate a statistically significant difference.

\section{Results}

ITR-284 inhibits cell growth in human hepatocellular and colorectal cancer cells. Our previous study reported that ITR-284 is capable of inhibiting cell growth of HL-60 and WEHI-3 leukemia cells (8). In the present study, we investigated the growth inhibition effect of ITR-284 on human hepatocellular cancer cells (Hep G2, Hep 3B, SK-HEP-1 and J5) and colorectal cancer cells (HT 29, COLO 205, HCT 116 and SW 620). The anti-proliferative effects of ITR-284 on those cells were evaluated by the MTT assay. As shown in Fig. 2, exposure to various concentrations of ITR-284 (0, 20, $40,60,80$ and $100 \mathrm{nM}$ ) for $48 \mathrm{~h}$ resulted in dose-dependent decreases in cell viability of Hep G2 (Fig. 2A), Hep 3B (Fig. 2B), SK-HEP-1 (Fig. 2C) and J5 cells (Fig. 2D). In Fig. 3, we observed that ITR-284 (0, 20, 40, 60, 80 and $100 \mathrm{nM})$ also dose-dependently reduced cell viability of HT 29 (Fig. 3A), COLO 205 (Fig. 3B), HCT 116 (Fig. 3C) and SW 620 cells (Fig. 3D). The results presented in Table I show the $\mathrm{EC}_{50}$ values of ITR-284 in various cancer cell lines. Our results demonstrated that the ITR-284 had highly selective effects on Hep 3B and COLO 205 cells in vitro.

ITR-284 induces apoptosis in Hep 3B and COLO 205 cells. ITR-284-induced reduction of cell viability may be due to apoptosis. A 48-h exposure to $50 \mathrm{nM}$ ITR-284 caused the Hep 3B cells (Fig. 4A) and COLO 205 cells (Fig. 4B) to round and shrink morphologically. Treatment of Hep 3B and COLO 205 cells with $50 \mathrm{nM}$ of ITR-284 also induced the 
A

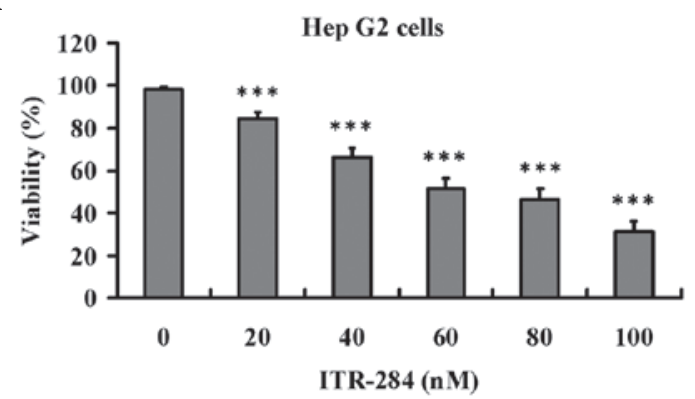

C

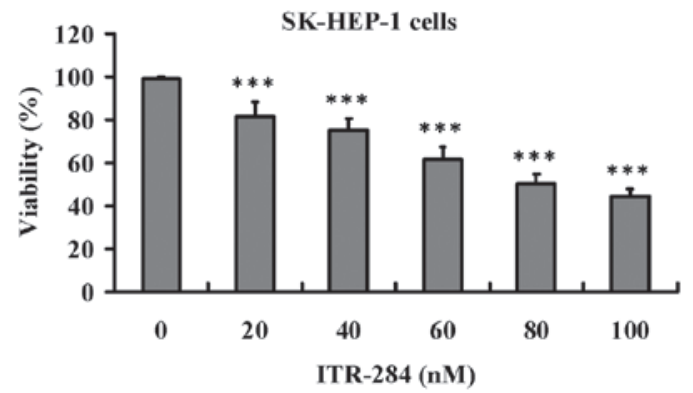

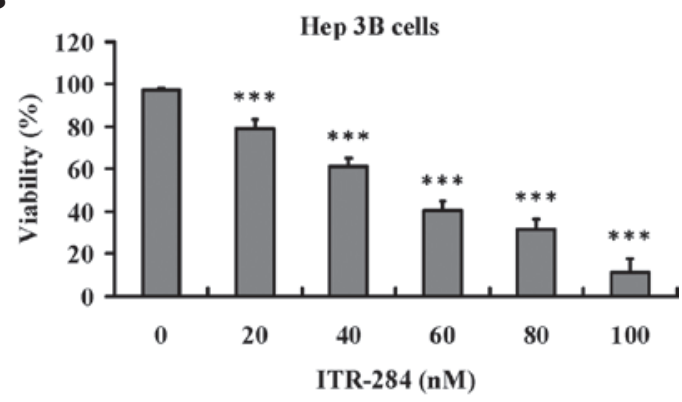

D

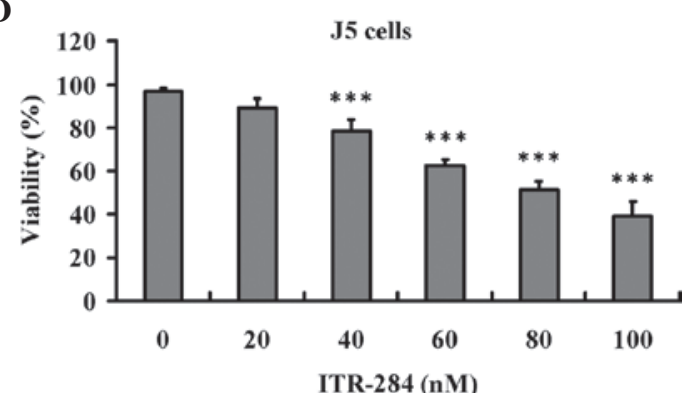

Figure 2. Effects of ITR-284 on cell viability in human hepatocellular cancer cell lines. Approximately $2 \times 10^{4}$ cells/well were plated onto 96 -well plates and then exposed to ITR-284 (0, 20, 40, 60, 80 and $100 \mathrm{nM}$ ) for $48 \mathrm{~h}$, and $0.1 \%$ DMSO in media served as a vehicle control. The cell viability of (A) Hep G2, (B) Hep 3B, (C) SK-HEP-1 and (D) J5 cells after 24 and $48 \mathrm{~h}$ of ITR-284 treatment were determined using the thiazolyl blue tetrazolium bromide (MTT) assay as described in Materials and methods. Each point is the mean \pm SEM of three independent experiments. ${ }^{* * *} \mathrm{P}<0.001$ compared with the control $(0 \mathrm{nM}$ ITR-284).

A

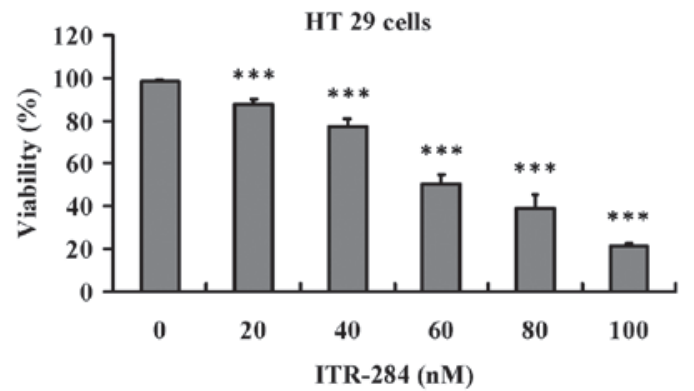

C

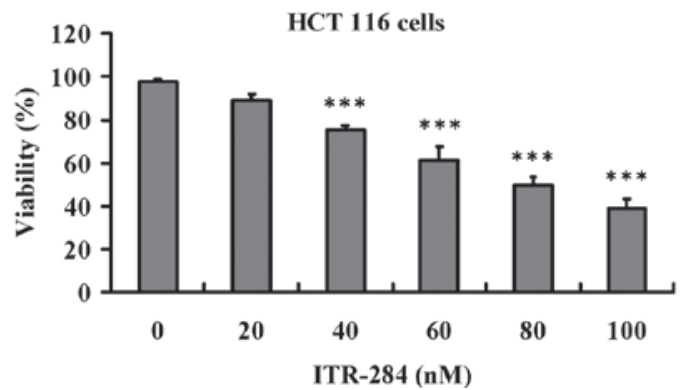

B

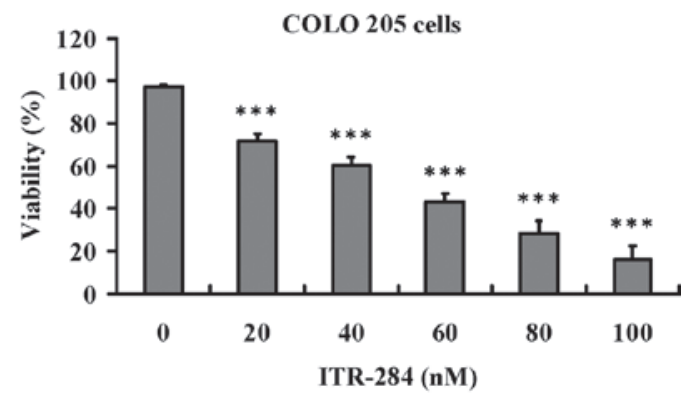

D

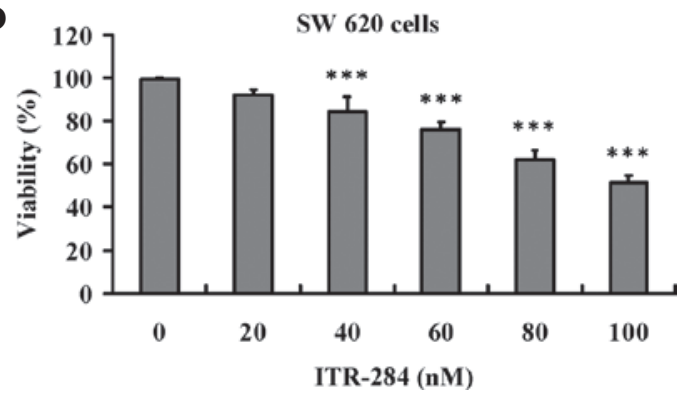

Figure 3. Effects of ITR-284 on cell viability in human colorectal cancer cell lines. Cells ( $2 \times 10^{4}$ cells/well) were incubated in the absence or presence of 0 , 20, 40, 60, 80 and $100 \mathrm{nM}$ of ITR-284 for 48 h. Cytotoxic effects on ITR-284-treated (A) HT 29, (B) COLO 205, (C) HCT 116 and (D) SW 620 cells were determined using the thiazolyl blue tetrazolium bromide (MTT) assay as described in Materials and methods. The data are presented as the means \pm SEM in triplicate by comparing the treated and untreated control cells. ${ }^{* * *} \mathrm{P}<0.001$ compared with the control (0 nM ITR-284).

translocation of phosphatidylserine (PS) from the inner side of the plasma membrane to the outer layer of the cell membrane by Annexin V analysis (data not shown). Our results indicated that ITR-284 treatments provoked apoptosis in human hepatocellular cancer Hep 3B and colorectal cancer COLO 205 cells.
ITR-284-triggered apoptosis involves the activation of caspase-3, - 8 and -9. To determine whether caspases are majorly involved in ITR-284-induced apoptotic cell death, the caspase-3, -8 and -9 activities were examined using the caspase colorimetric activity assay. Our results demonstrated that 
Table I. In vitro cytotoxicity of ITR-284.

\begin{tabular}{llr}
\hline Cell line & \multicolumn{1}{c}{ Cell type } & \multicolumn{1}{c}{$\mathrm{EC}_{50}{ }^{\mathrm{a}}(\mathrm{nM})$} \\
\hline Hep G2 & Human hepatoblastoma & $86.39 \pm 4.18$ \\
Hep 3B & Human hepatocellular carcinoma & $51.23 \pm 2.98$ \\
SK-HEP-1 & Human hepatocarcinoma cells & $95.69 \pm 3.25$ \\
J5 & Human hepatocellular carcinoma & $106.25 \pm 4.40$ \\
HT 29 & Human colorectal adenocarcinoma & $76.58 \pm 6.25$ \\
COLO 205 & Human colon adenocarcinoma & $47.56 \pm 3.69$ \\
HCT 116 & Human colorectal carcinoma & $96.25 \pm 5.58$ \\
SW 620 & Human colorectal adenocarcinoma & $126.32 \pm 4.01$
\end{tabular}

${ }^{\mathrm{a} C}$ Concentration of compound which afforded $50 \%$ reduction in cell number for a 48 -h treatment.

\section{A Hep 3B cells}

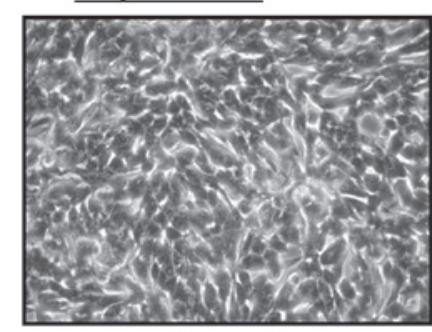

Control

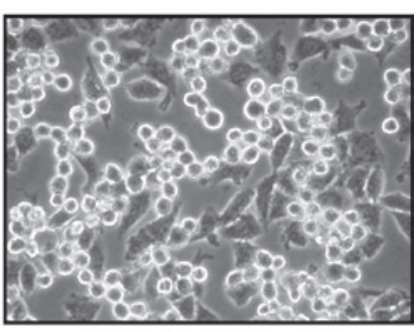

ITR-284 (50 $\mathrm{nM})$

\section{B COLO 205 cells}

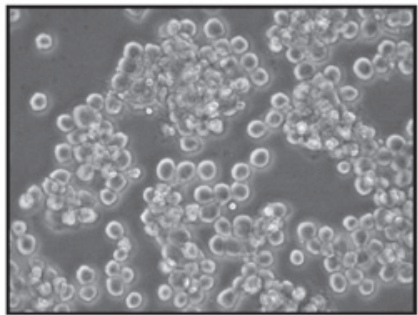

Control

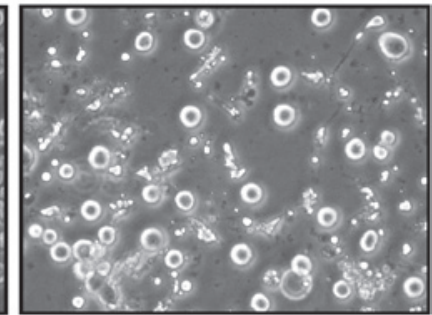

ITR-284 (50 nM)
Figure 4. ITR-284 caused apoptotic morphological changes in Hep 3B and COLO 205 cells. (A) Hep 3B and (B) COLO 205 cells treated with $50 \mathrm{nM}$ ITR-284 for $48 \mathrm{~h}$ were consequently photographed under a phase-contrast microscope (magnification, x200) to determine apoptotic morphological changes. Data were obtained from three independent experiments with similar results.

caspase-3, -8 and -9 activities were all elevated following $48 \mathrm{~h}$ of exposure to $50 \mathrm{nM}$ ITR-284 in both Hep 3B (Fig. 5A) and COLO 205 cells (Fig. 5B). We suggested that ITR-284-induced apoptosis occurs through the induction of caspase- $3,-8$ and -9 activities.

Effects of caspase-3, -8 and -9 inhibition on apoptosis in ITR-284-treated cells. The aforementioned results showed that ITR-284-induced apoptosis occurs through the activation of caspase-3, -8 and -9 activities. In the present study, Hep 3B and COLO 205 cells were pre-treated with $10 \mu \mathrm{M}$ caspase-3, -8 and -9 inhibitors for $1 \mathrm{~h}$, and then exposed to $50 \mathrm{nM}$ ITR-284. Subsequently, cells were harvested for
A Hep 3B cells

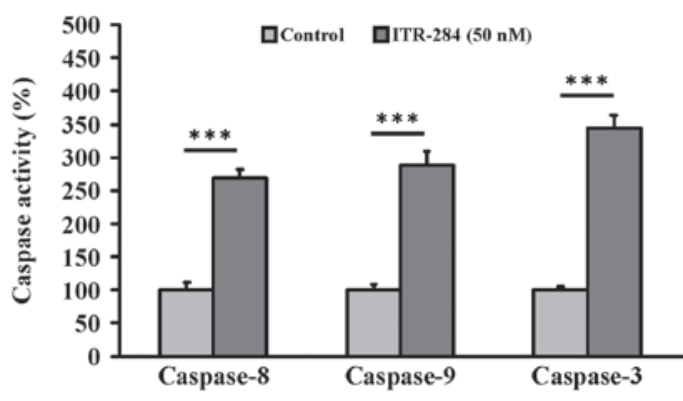

B COLO 205 cells

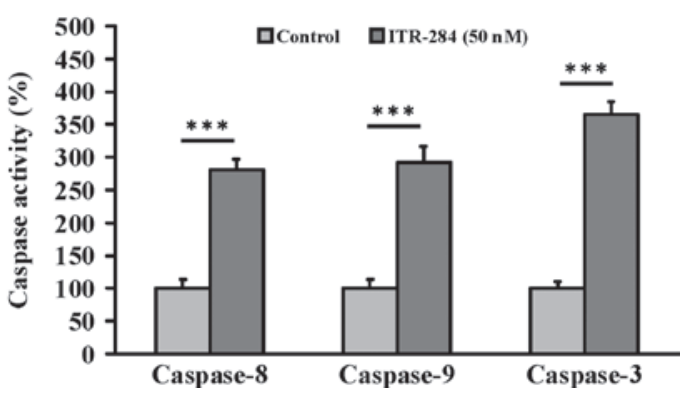

Figure 5. Effects of ITR-284 on caspase-3, -8 and -9 activities of Hep 3B and COLO 205 cells. (A) Hep 3B and (B) COLO 205 cells were treated with $50 \mathrm{nM}$ ITR-284 and then incubated for $48 \mathrm{~h}$, and the whole-cell lysate was subjected to caspase activity assay. Each result is shown as the mean \pm SEM in triplicate by comparing the treated and untreated control cells. ${ }^{* * *} \mathrm{P}<0.001$ compared with the control.

$\mathbf{A}$

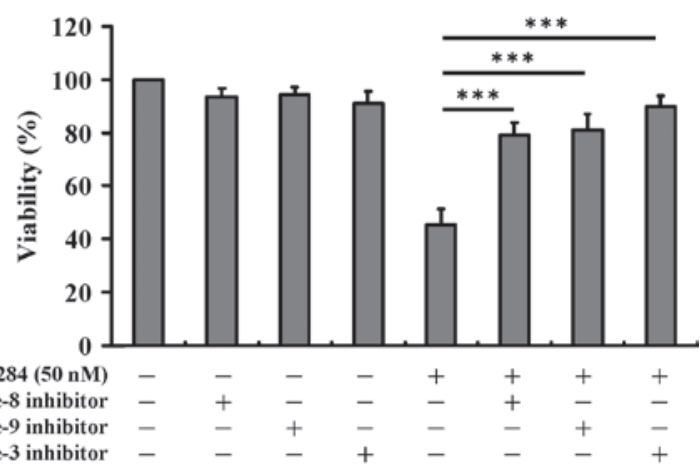

B

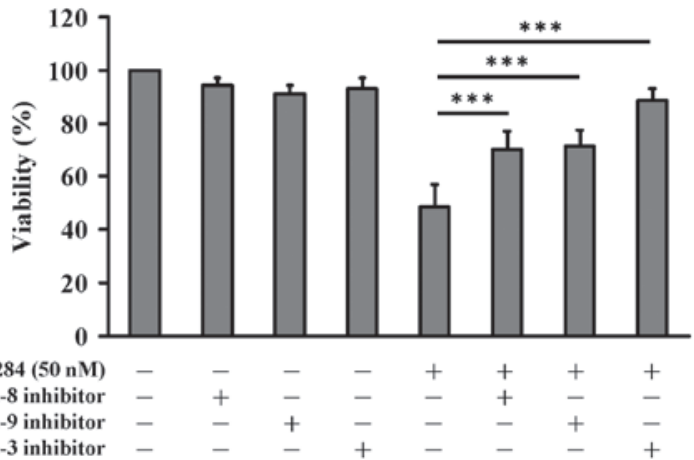

Figure 6. Caspase- $3,-8$ and -9 are required for ITR-284-triggered apoptosis of Hep 3B and COLO 205 cells. (A) Hep 3B and (B) COLO 205 cells were exposed to $50 \mathrm{nM}$ ITR-284 for $48 \mathrm{~h}$ prior to pretreatment with or without $10 \mu \mathrm{M}$ of caspase-3, -8 and -9 inhibitors, respectively, as described in Materials and methods. All results are expressed as the means \pm SEM in triplicate by comparing the treated and untreated control cells. ${ }^{* * * *} \mathrm{P}<0.001$ compared with the control. 
measuring the cell viability by MTT assay. Pre-incubation with caspase- $3,-8$ and -9 specific inhibitors significantly reduced ITR-284-induced viability in Hep 3B (Fig. 6A) and COLO 205 cells (Fig. 6B). Our results suggest that caspase-3, -8 and -9 activation may be involved in ITR-284-induced apoptotic cell death.

\section{Discussion}

ITR-284 is a prospective anticancer compound and was first described and synthesized in cooperation with the laboratory of Dr. Yen-Fang Wen. An earlier study has verified that ITR-284 significantly inhibited the cell proliferation of human leukemia cells (8). Furthermore, ITR-284 has much less cytotoxicity in normal peripheral blood mononuclear cells (PBMCs) than in leukemia cells (8). The previous study has demonstrated that ITR-284 (30 $\mathrm{nM})$ substantially inhibits the growth of HL60 and WEHI-3 leukemia cells in vitro. In a leukemia orthotopic model, ITR-284 significantly prolonged the survival rate, prevented body weight loss, inhibited spleen enlargement and reduced infiltration of immature myeloblastic cells into splenic red pulp in an in vivo experiment (8). However, combined treatment of ITR-284 with ATRA is more effective for differentiation therapy of leukemia. Our data indicated that ITR-284 represents a promising candidate as an anticancer drug with low toxicity to normal cells (8). The purpose of this study was to determine whether ITR-284 affects cell growth, and we investigated cell death signaling pathways and induction of apoptosis in human hepatocellular and colorectal cancer cells.

A number of studies have showed that the carboxamide derivatives function via certain molecular mechanisms, including the inhibition of topoisomerase activities and the induction of apoptosis (15-17). In the present study, our results demonstrate that ITR-284 treatment decreased the viability (Figs. 2 and 3 ) of human hepatocellular cancer cells (Hep G2, Hep 3B, SK-HEP-1 and J5) and colorectal cancer cells (HT 29, COLO 205, HCT 116 and SW 620). ITR-284 may cause cytotoxicity by inducing cell death. Notably, the $\mathrm{EC}_{50}$ for 48-h treatment of ITR-284 in hepatocellular and colorectal cancer cell lines was different (Table I); one of the reasons for the differences in sensitivities of different cell lines may be the inherent different doubling time in various cell lines, and another reason may be the differential gene expression in various cell types. It is well known that Hep G2, J5 and SK-HEP-1 cell lines are p53-positive, but Hep 3B cells are p53-negative. HT 29, COLO 205 and SW 620 lines have p53 mutation, but the HCT 116 cell line has wild-type p53.

This is the first study to investigate the anticancer effects of ITR-284 on human hepatocellular and colorectal cancer cells, and the results suggest that ITR-284 induced apoptotic cell death and inhibited the growth of cancer cells in a concentration-dependent manner. This observation is similar to our earlier study addressing ITR-284, which showed that ITR-284 initially affected the induction of apoptosis in HL60 and WEHI-3 leukemia cell lines. As shown in Fig. 5, ITR-284 induced apoptosis through the activation of caspases-3, -8 and -9 in Hep 3B and COLO 205 cells. These results suggest that the anticancer activity of ITR-284 occurs through the induction of apoptotic cell death. Hep 3B and COLO 205 cells were pretreated with caspase- $3,-8$ and -9 inhibitors and then exposed to ITR-284, leading to increases in the percentage of viable cells when compared with the ITR-284-treated only cells (Fig. 6). Our data indicated that these three caspases $(-3,-8$ and -9$)$ were activated following ITR-284 treatment. Thus, we proposed that ITR-284-induced apoptosis may be carried out through the extrinsic and intrinsic signaling pathways.

In conclusion, ITR-284 has growth inhibition effects on human hepatocellular cancer cells (Hep G2, Hep 3B, SK-HEP-1 and J5) and colorectal cancer cells (HT 29, COLO 205, HCT 116 and SW 620) by inducing cell apoptosis. Our study has clearly revealed that the activation of caspase- $3,-8$ and -9 is the major pharmacological action of ITR-284. Based on our results, ITR-284 has the potential to become one of the leading compounds for the development of a novel antihepatocellular and colorectal cancer agent in the future.

\section{Acknowledgements}

This study was supported by a research grant from the National Science Council of the Republic of China awarded to Dr TianShung $\mathrm{Wu}$ and a grant from the China Medical University (CMU-99-pharmacy-01 and CMU-99-pharmacy-02).

\section{References}

1. Zimonjic DB, Keck CL, Thorgeirsson SS and Popescu NC: Novel recurrent genetic imbalances in human hepatocellular carcinoma cell lines identified by comparative genomic hybridization. Hepatology 29: 1208-1214, 1999.

2. Nowak AK, Chow PK and Findlay M: Systemic therapy for advanced hepatocellular carcinoma: a review. Eur J Cancer 40: 1474-1484, 2004

3. Ma CY, Ji WT, Chueh FS, Yang JS, Chen PY, Yu CC and Chung JG: Butein inhibits the migration and invasion of SK-HEP-1 human hepatocarcinoma cells through suppressing the ERK, JNK, p38, and uPA signaling multiple pathways. J Agric Food Chem 59: 9032-9038, 2011.

4. Lu CC, Yang JS, Chiang JH, Hour MJ, Lin KL, Lin JJ, Huang WW, Tsuzuki M, Lee TH and Chung JG: Novel quinazolinone MJ-29 triggers endoplasmic reticulum stress and intrinsic apoptosis in murine leukemia WEHI-3 cells and inhibits leukemic mice. PLoS One 7: e36831, 2012.

5. Yang JS, Hour MJ, Huang WW, Lin KL, Kuo SC and Chung JG: MJ-29 inhibits tubulin polymerization, induces mitotic arrest, and triggers apoptosis via cyclin-dependent kinase 1-mediated Bcl-2 phosphorylation in human leukemia U937 cells. J Pharmacol Exp Ther 334: 477-488, 2010.

6. Kelloff GJ, Crowell JA, Steele VE, et al: Progress in cancer chemoprevention: development of diet-derived chemopreventive agents. J Nutr 130: 467S-471S, 2000.

7. Lavrik IN, Golks A and Krammer PH: Caspases: pharmacological manipulation of cell death. J Clin Invest 115: 2665-2672, 2005.

8. Wen YF, Lee KH, Huang PT, Chen MH, Shin WC, Huang LJ, Hsu MH, Chen CJ and Kuo SC: Cell differentiation enhancement by hydrophilic derivatives of 4,8-dihydrobenzo[1,2-b:5,4-b'] dithiophene-4,8-diones in HL-60 leukemia cells. Bioorg Med Chem Lett 17: 2908-2912, 2007.

9. Wen YF, Yang JS, Kuo SC, Hwang CS, Chung JG, Wu HC, Huang WW, Jhan JH, Lin CM and Chen HJ: Investigation of anti-leukemia molecular mechanism of ITR-284, a carboxamide analog, in leukemia cells and its effects in WEHI-3 leukemia mice. Biochem Pharmacol 79: 389-398, 2010.

10. Ip SW, Wei HC, Lin JP, Kuo HM, Liu KC, Hsu SC, Yang JS, Mei-Dueyang, Chiu TH, Han SM and Chung JG: Bee venom induced cell cycle arrest and apoptosis in human cervical epidermoid carcinoma Ca Ski cells. Anticancer Res 28: 833-842, 2008. 
11. Lin ML, Chen SS, Lu YC, Liang RY, Ho YT, Yang CY and Chung JG: Rhein induces apoptosis through induction of endoplasmic reticulum stress and $\mathrm{Ca}^{2+}$-dependent mitochondrial death pathway in human nasopharyngeal carcinoma cells. Anticancer Res 27: 3313-3322, 2007.

12. Yang JS, Chen GW, Hsia TC, Ho HC, Ho CC, Lin MW, Lin SS, Yeh RD, Ip SW, Lu HF and Chung JG: Diallyl disulfide induces apoptosis in human colon cancer cell line (COLO 205) through the induction of reactive oxygen species, endoplasmic reticulum stress, caspases casade and mitochondrial-dependent pathways. Food Chem Toxicol 47: 171-179, 2009.

13. Yang JS, Hour MJ, Kuo SC, Huang LJ and Lee MR: Selective induction of G2/M arrest and apoptosis in HL-60 by a potent anticancer agent, HMJ-38. Anticancer Res 24: 1769-1778, 2004.

14. Packard BZ, Toptygin DD, Komoriya A and BrandL: Profluorescent protease substrates: intramolecular dimers described by the exciton model. Proc Natl Acad Sci USA 93: 11640-11645, 1996.
15. Lukka PB, Kestell P, Paxton JW and Baguley BC: Development and validation of a liquid chromatography-mass spectrometry (LC-MS) assay for the determination of the anti-cancer agent $\mathrm{N}$-[2-(dimethylamino)ethyl]-2,6-dimethyl-1-oxo-1,2dihydrobenzo[b]-1,6-naph thyridine-4-carboxamide (SN 28049). J Chromatogr B Analyt Technol Biomed Life Sci 875: 368-372, 2008.

16. Feng W, Satyanarayana M,Tsai YC,Liu AA,Liu LF and LaVoie EJ: 11-Substituted 2,3-dimethoxy-8,9-methylenedioxybenzo[i]phenanthridine derivatives as novel topoisomerase I-targeting agents. Bioorg Med Chem 16: 8598-8606, 2008.

17. Creighton-Gutteridge M, Cardellina JH II, Stephen AG, Rapisarda A, Uranchimeg B, Hite K, Denny WA, Shoemaker RH and Melillo G: Cell type-specific, topoisomerase II-dependent inhibition of hypoxia-inducible factor-1alpha protein accumulation by NSC 644221. Clin Cancer Res 13: 1010-1018, 2007. 